\title{
The Effect of Chitosan Prepared in Different Solvents on the Quality Parameters of Brown Trout Fillets (Salmo trutta fario)
}

\section{Gonca Alak}

Department of Agricultural Biotechnology, Agriculture Faculty, Atatürk University, Erzurum, Turkey.

Email: galak@atauni.edu.tr

Received July $24^{\text {th }}, 2012$; revised August $24^{\text {th }}, 2012$; accepted September $2^{\text {nd }}, 2012$

\begin{abstract}
In this study, the use of chitosan prepared in different solvents (acetic acid, lactic acid) as a coating material was researched. The lowest mean $\mathrm{pH}$, TBARS and TVB-N values among the treatment groups were observed in the acetic acid group. Similarly, the lowest growth of aerobic, lactic acid and Pseudomonas bacteria was recorded in this group. The growth of aerobic bacteria in the fillets that were packaged using chitosan film, was lower than the control group throughout the trial. The number of Pseudomonas and lactic acid bacteria was statistically higher in the fillets in the control groups compared to the groups with chitosan $(\mathrm{p}<0.01)$. As a result, it is thought that the use of acetic acid in chitosan film coating is more convenient for the preservation of fish, compared to lactic acid.
\end{abstract}

Keywords: Lactic Acid; Acetic Acid; Brown Trout; Quality

\section{Introduction}

Fish are a frequently preferred food, due to their protein quality and nutrient values, particularly in recent years. However, fish meat, due to its chemical composition and its properties as a good substrate for decomposing microorganisms, can easily spoil. The shelf life of these products under regular refrigerator conditions is classified using microbiological, enzymatic and chemical decompositions [1].

When the recent tendency towards the consumption of these products gained importance, not only considering quality, but also considering safety, the rise in the concerns on the destruction of traditional synthetic plastic material drew attention to renewable natural coating materials [2]. Chitosan is the name used for low acetyl substituted forms of chitin and is composed primarily of glucosamine, 2-amino-2-deoxy-b-d-glucose, known as $(1 \rightarrow 4)$-2-amino-2-deoxy-(d-glucose). Chemical modifications of these groups have provided numerous useful materials in different fields of application [3]. Chitosan, which is a natural product, can be used as a coating material for the storage of fish for its effects on texture [4], as well as its antimicrobial [5,6] and antioxidant [7] properties. In this trial, the chemical $(\mathrm{pH}$, total volatile base nitrogenTVB-N and lipid oxidation-TBARS) and microbial (numbers of mesophilic, Lactic acid, and Pseudomonas bacteria) properties of the vacuum-packaged brown trout fillets after storage at $4^{\circ} \mathrm{C} \pm 1{ }^{\circ} \mathrm{C}$, which were coated with chitosan film, prepared with different solvents, were analyzed.

\section{Material and Method}

The trial was conducted at $4^{\circ} \mathrm{C} \pm 1{ }^{\circ} \mathrm{C}$ with 3 different treatment groups [only vacuum-packaged fillets (control), the group of vacuum packaged fillets coated with chitosan prepared using acetic acid (AC), and the group of vacuum packaged fillets coated with chitosan prepared using lactic acid (L)] with different storage periods $(0,3$, 6,9 and 12 days) at $3 \times 5$ factorial design according to a randomized trial plan, and was set up and conducted with two replicates.

\subsection{Fish Material Used in the Trial}

In the trial, 60 brown trouts (Salmo trutta fario), each weighing $180 \mathrm{~g}$ on average, which were obtained from Atatürk University Faculty of Aquaculture, were used as fish material.

\subsection{Packaging Material Used in the Trial}

A $15 \times 25 \mathrm{~cm}, 65 \mu \mathrm{m}$ material that consisted of $15 \mu \mathrm{m}$ OA/EVOH PE (Oriented Polyamide EVOH Polyethylene) from UPM (UPM-Kymmene Corporation Walki Films, Finland), and $50 \mu \mathrm{m}$ polyethylene $\left(\mathrm{O}_{2}\right.$ permeability 5 $\mathrm{cm}^{3} / \mathrm{m}^{2} /$ day atm. $23^{\circ} \mathrm{C} ; \mathrm{N}_{2}$ permeability $1 \mathrm{~cm}^{3} / \mathrm{m}^{2} /$ day atm. 
$23^{\circ} \mathrm{C} ; \mathrm{CO}_{2}$ permeability $23 \mathrm{~cm}^{3} / \mathrm{m}^{2} /$ day atm. $23^{\circ} \mathrm{C}$ and water vapor permeability $15 \mathrm{~g} / \mathrm{m}^{2} /$ day atm. $38^{\circ} \mathrm{C}$ ) was used.

\subsection{Preparation of Chitosan Film}

The low-viscosity chitosan was obtained from SigmaAldrich. Solutions of $1.5 \%$ chitosan were prepared by solving $7.5 \mathrm{~g}$ chitosan in $500 \mathrm{ml} 1.5 \%$ acetic acid and $500 \mathrm{ml}$ $1.5 \%$ lactic acid. In order to completely solubilize chitosan, the solutions were mixed at room temperature for one night using a mixer. After chitosan was completely solubilized, it was filtered using cheesecloth to remove impurities (mesh width approx. $1 \mathrm{~mm}^{2}$ ). In the end, the prepared solution was poured onto Teflon-coated pans, the films were taken out of pans after being dried at room temperature for a minimum of 72 hours. The resulting films were kept in the acclimatization cabin at $25^{\circ} \mathrm{C}$ [2].

\subsection{Preparation of Fillets}

Brown trouts were brought to the laboratory and eviscerated. The fish were laterally placed on the laboratory table. Slabs of meat, which consisted of dorsal and abdominal muscles, from the bottom of gill cover to the caudal fins, were separated using sharp lancets. The fish were rotated and the same procedures were applied. The heads were separated along with the bones, tails and gills, thus resulting in the fillets [8].

\subsection{The Coating of Fillets with Chitosan and Packaging}

Fillets were divided into 3 groups and each group had 40 fillets. The first group was the control group, which consisted of vacuum-packaged fillets only. The second group of fillets was coated with chitosan film, which was prepared with acetic acid, and was vacuum-packaged. The fillets in the third group were coated with chitosan film, which were prepared with lactic acid, and were vacuum-packaged. In the trial, the fillets were preserved at $4^{\circ} \mathrm{C} \pm 1^{\circ} \mathrm{C}$ for 12 days.

\subsection{Chemical Analyses}

The samples that were used in the chemical analysis of the fillets were finely chopped using lancets under aseptic conditions. Three parallels of 10 gram samples were taken, which were made smaller and $100 \mathrm{ml}$ distilled water was added onto each sample. The mixture was homogenized in Ultra Turrax for 1 minute and the $\mathrm{pH}$ values were measured using a $\mathrm{pH}$ meter (SCHOTT, Lab $\mathrm{Star} \mathrm{pH})$. The $\mathrm{pH}$ meter was calibrated using $\mathrm{pH} 4.00$ and $\mathrm{pH} 7.00$ buffer solutions before measuring. The total volatile base-nitrogen amount (TVB-N) and thiobarbituric acid reactive substance (TBARS) value in fish was determined according to [2].

\subsection{Microbiological Analyses}

A sample of $25 \mathrm{~g}$ was taken for microbiological analysis, and $225 \mathrm{ml}$ sterile physiological saline solution $(0.85 \%$ $\mathrm{NaCl}$ ) was added to the sample. The mixture was homogenized in a Stomacher Blender (Lab Stomacher Blender 400-BA7021, Sewardmedical). The proper dilutions were prepared by taking samples from this homogenate. Plate Count Agar (PCA, Merck) was used as a medium for the total bacteria count. The dilutions were spread on petri dishes using the spread plate method, and the petri dishes were incubated for 2 days at $37^{\circ} \mathrm{C}$, for mesophilic bacteria count. The lactic acid bacteria count was performed after the incubation of the petri dishes with MRS agar for 3 days at $30^{\circ} \mathrm{C}$. Pseudomonas bacteria count was taken after the incubation of petri dishes with C-F-C (Cetrimide-Fucidin-Cephloridine) added to Pseudomonas agar for 2 days at $25^{\circ} \mathrm{C}$. There were two parallels of each culture and the results were given in $\log _{10} \mathrm{CFU} / \mathrm{g}$ [2].

\subsection{Statistical Analyses}

The trial data were analyzed with variance analysis using SPSS package software, and the mean values of significant variation sources were compared using the Duncan Multiple Comparison Test [9].

\section{Results and Discussion}

The chemical parameters ( $\mathrm{pH}$, TBARS, TVB-N) of brown trout fillets were significant at $p<0.01$ considering the difference between groups and groups' day interactions. It was observed that the $\mathrm{pH}$ values of fillets from each group slightly decreased until the third day of the trial, and later started to increase (Figure 1(a)). The lowest $\mathrm{pH}$ value of the trial was observed in the group with the fillets that were coated with chitosan prepared with acetic acid $(6.44 \pm 0.01)$. It is believed that this was caused by acetic acid that was used for the preparation of the chitosan solution. [10] suggested that acetic acid released from chitosan was much slower than acids like lactic acid.

It was found that the TVB-N values of no treatment groups exceeded the critical value of $25 \mathrm{mg} / 100 \mathrm{~g}$ on day 12 of the storage period. However, higher values were obtained in the control group contrary to other groups, and the value was $17.38 \pm 0.3 \mathrm{mg} / 100 \mathrm{~g}$ on the last day of storage period (Figure 1(b)). [5] reported that the TVB- N value was $35 \%$ to $50 \%$ less than the control group in the cod fish fillets that were coated with different types pf-soluble chitosan. Furthermore, [11] found that the TVB-N value remained constant during the 25 -day storage period, in cod fish sausages that received 5\% chitosan and were processed under high pressure. However, [12] could not find any significant effect of chitosan, which was used as a coating material, on TVB-N values. 


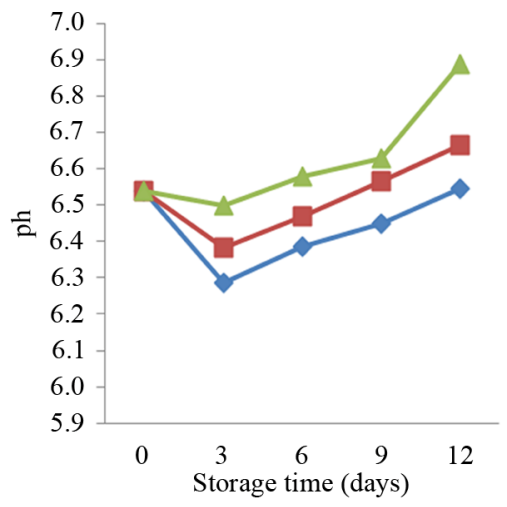

(a)

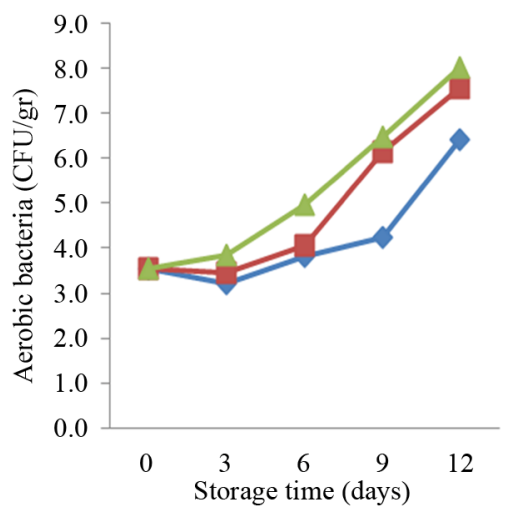

(d)

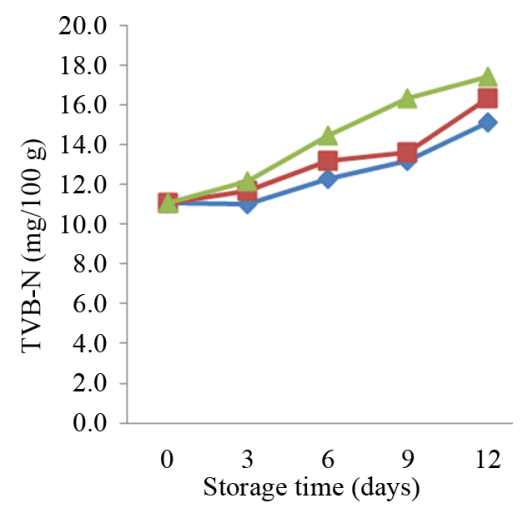

(b)

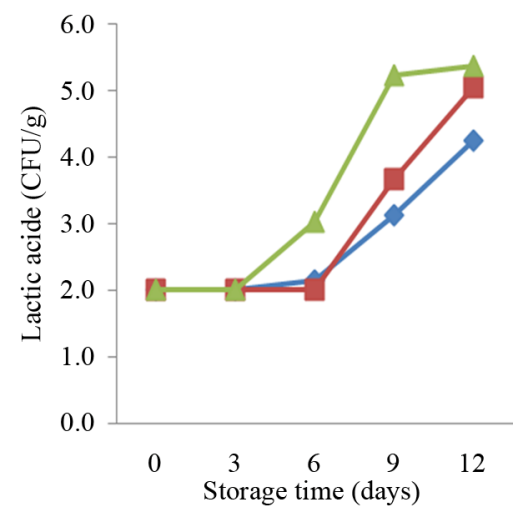

(e)

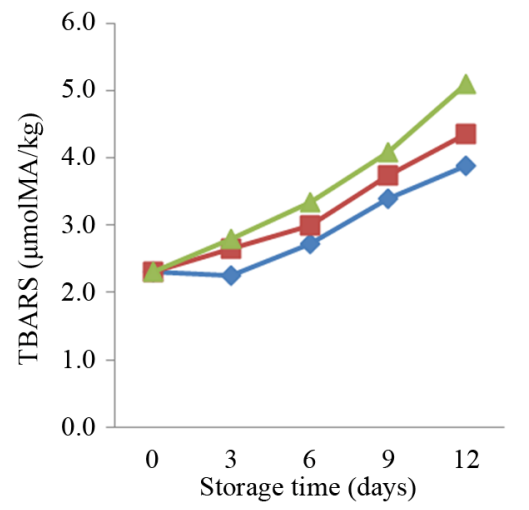

(c)

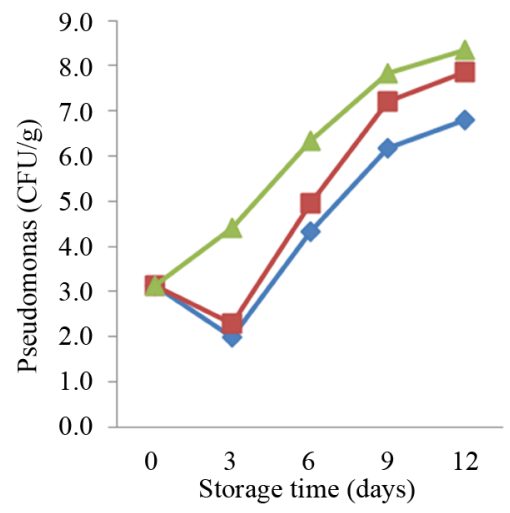

(f)

vacuum acetic acide; $\square$ vacuum lactic acide; $-\boldsymbol{\sim}$ vacuum control.

Figure 1. Changes in mesophilic counts (a) Lactic acid bacteria counts; (b) Pseudomonas counts; (c) pH values; (d) TBARS levels; (e) TVB-N levels; (f) On brown trout fillets coated with chitosan solution with different solvent in packaged vacuum and storaged at $4^{\circ} \mathrm{C}$. Upper areas of horizontal lines are unacceptable in each graph $(\mathrm{n}=3)$.

Another chemical parameter of fish meat consumption is the TBARS value. During the 12-day trial period, the TBARS values of the groups that were treated with acetic acid and lactic acid were very similar, but this value showed a rapid increase in the control group after day 3 of the trial (Figure 1(c)). [13] analyzed the antioxidant effect of the addition of chitosan on processed herring, and observed that chitosan showed an antioxidant effect and the TBARS value in the samples that were treated with chitosan dropped $61 \%$ compared to the control group, after 8 storage days. Similarly, it was reported that the addition of $0.2 \%, 0.5 \%$ and $1 \%$ chitosan with different molecular weights decreased lipid oxidation in salmon [14].

It was observed that the aerobic bacteria growth was lower in the fillets, which were packaged with chitosan film, compared to the control group $(p<0.01)$ (Figure 1(d)). On day 9 of the trial, the number of mesophilic bacteria reached the critical level of $10^{6} \mathrm{CFU} / \mathrm{g}$ in the control group while this number was $10^{5}$ and $10^{4} \mathrm{CFU} / \mathrm{g}$ in the groups with chitosan. The numbers of Pseudomonas, and lactic acid bacteria were statistically lower in the groups with chitosan, compared to the fillets in the control group $(p<0.01)$ (Figures 1(e) and (f)).

The number of Enterobacteriacea of the fillets that were prepared in different solvents was lower than the control group ( $\mathrm{p}<0.05$ ) but the number of Enterobacteriacea increased in all groups as time elapsed.

Many studies were conducted on the antimicrobial properties of chitosan. In a study with cod fish, it was found that chitosan coating had an inhibitory effect on gramnegative bacterial flora [11]. [15] analyzed the effect of preparation methods and the deacetylation level on the antimicrobial activity of chitosan. Chitin, which was prepared by chemical method (CH-chitin) and prepared by microbial method (MO-chitin), was derived from crab shell. $\mathrm{CH}$-chitin and $\mathrm{MO}$-chitin were deacetylated from various chitosan products, where deacetylation level was low between $47 \%-53 \%$, moderate at $74 \%-46 \%$ and high at $95 \%-97 \%$. Chitin was cultivated for antimicrobial and anti fungal tests. Chitosan was added to salmon (Oncorhynchus nerka) fillets for bacterial tests. MO-chitin and CH-chitin did not show any antimicrobial activity. The antimicrobial activity increased with the increase in the deacetylation value of chitosan and was effective against 
bacteria, rather than fungi. The lethal concentration of chitosan, which has a high level of deacetylation, between 50 - 200 ppm, was effective against Bacillus cereus, Escherichia coli, Litreria monocytogenes, Pseudomonas aeruginosa, Shigella dysenteriae, Staphylococcus aureus, Vibrio cholere and V. parahaemolyticus, while the minimum lethal concentration between 200 - 500 ppm was effective against Candia albicans and Fusarium oxysporum. As a result, chitosan, which has a high deacetylation level, preserved fish fillets against several bacteria and prolonged their shelf life.

As a result, considering the obtained data, coating with chitosan film which is prepared in different solutions is an alternative to traditional fish preservation methods. However, coating with chitosan, which was prepared using acetic acid, had a positive effect on the microbiological and chemical parameters of brown trout (Salmo trutta fario) fillets and the parameters in this group were lower than the other groups. Particularly, coating with chitosan yielded better results in non-oily fish like trout, compared to oily fish.

\section{REFERENCES}

[1] I. N. A. Ashie, J. P. Smith and B. K. Simpson, "Spoilage and Shelf-Life Extension of Fresh Fish and Shellfish," Critical Reviews in Food Science and Nutrition, Vol. 36, No. 1-2, 1996, pp. 121-127. doi:10.1080/10408399609527720

[2] G. Alak, S. A. Hisar, O. Hisar, G. Kaban and M. Kaya, "Microbiological and Chemical Properties of Bonito Fish (Sarda sarda) Fillets Packaged with Chitosan Film, Modified Atmosphere and Vacuum," Journal of the Faculty of Veterinary Medicine, University of Kafkas, Vol. 16, 2010, pp. 73-80.

[3] F. Shahidi, J. K. V. Arachchi and Y. Jeon, "Food Applications of Chitin and Chitosans," Trends in Food Science \& Technology, Vol. 10, 1999, pp. 37-51.

[4] S. Benjakul, W. Visessanguan, S. Phatchrat and M. Tanaka, "Chitosan Affects Transglutaminase-Induced Surimi Gelation," Journal of Food Biochemistry, Vol. 27, No. 1, 2003, pp. 53-66. doi:10.1111/j.1745-4514.2003.tb00266.x

[5] R. G. Cuero, "Antimicrobial Action of Exogenous Chitosan, Chitin and Chitinases," In: P. Jolles and R. A. A.
Muzarelli, Eds., Chitin and Chitinases, Birkhauser, Basel, 1999, pp. 315-333.

[6] Y. J. Jeon, J. Y. V. A. Kamil and F. Shahidi, "Chitosan as an Edible Invisible Film for Quality Preservation of Herring and Atlantic Cod," Journal of Agricultural and Food Chemistry, Vol. 50, No. 18, 2002, pp. 5167-5178. doi:10.1021/jf0116931

[7] J. Y. V. A. Kamil, Y. J. Jeon and F. Shahidi, "Antioxidative Activity of Chitosans of Different Viscosity in Cooked Comminuted Flesh of Herring (Clupea harengus)," Food Chemistry, Vol. 79, 2002, pp. 69-77. doi:10.1016/S0308-8146(02)00180-2

[8] Z. E. Sikorski, "Seafood, Resources, Nutritional Composition and Preservation," CRC Press, Inc., Boca Raton, 1990.

[9] G. W. Sneceder and W. G. Cochrani, "Istatistical Methods, S.XVII. 507," The Fowa State University Press, Ames, 1980.

[10] B. Ouattara, R. E. Simard, G. Piette, A. Begin and R. A. Holley, "Inhibition of Surface Spoilage Bacteria in Processed Meats by Application of Antimicrobial Films Prepared with Chitosan," International Journal of Food Microbiology, Vol. 62, 2000, pp. 139-148. doi:10.1016/S0168-1605(00)00407-4

[11] M. E. López-Caballero, M. C. Gómez-Guillén, M. PérezMateos and P. Montero, "A Chitosan-Gelatin Blend as a Coating for Fish Patties," Food Hydrocolloids, Vol. 19, 2005, pp. 303-311. doi:10.1016/j.foodhyd.2004.06.006

[12] M. E. López-Caballero, M. C. Góamez-Guillén, M. PérezMateos and E. Montero, "A Chitosan-Gelatin Blend as a Coating for Fish Patties," Journal of Food Science, Vol. 60, 2004, pp. 160-170.

[13] F. Shaidi, J. Kamil, Y. J. Jeon and S. K. Kim, "Antioxidant Role of Chitosan in Cooked Cod (Godus morhua) Model System," Journal of Food Lipids, Vol. 9, 2002, pp. 57-64. doi:10.1111/j.1745-4522.2002.tb00208.x

[14] K. W. Kyung and R. W. Thomas, "Antioxidative Activity of Chitosans with Varying Molecular Weights," Food Chemistry, Vol. 101, 2007, pp. 308-313. doi:10.1016/j.foodchem.2006.01.038

[15] T. Gua-Jane, W. H. Su, H. C. Chen and C. L. Pan, "Antimicrobiyal Activity of Shrimp Chitin and Chitosan from Different Treatments and Applications of Fish Preservation," Fisheries Science, Vol. 68, 2002, pp. 170-177. doi:10.1046/j.1444-2906.2002.00404.x 